University of Nebraska - Lincoln

DigitalCommons@University of Nebraska - Lincoln

USDA National Wildlife Research Center - Staff Publications
U.S. Department of Agriculture: Animal and Plant Health Inspection Service

October 2006

\title{
Rapid assessment for a new invasive species threat: the case of the Gambian giant pouched rat in Florida
}

\author{
Richard M. Engeman \\ USDA-APHIS-Wildlife Services, s_r100@yahoo.com \\ John W. Woolard \\ USDA/Wildlife Services \\ Neil D. Perry \\ Texas A\&M University, College Station \\ Gary W. Witmer \\ USDA-APHIS-Wildlife Services, gary.w.witmer@usda.gov

\section{Scott Hardin} \\ Florida Fish and Wildlife Conservation Commission
}

See next page for additional authors

Follow this and additional works at: https://digitalcommons.unl.edu/icwdm_usdanwrc

Part of the Environmental Sciences Commons

Engeman, Richard M.; Woolard, John W.; Perry, Neil D.; Witmer, Gary W.; Hardin, Scott; Brashears, Lawrence; Smith, Henry ; Muiznieks, Britta; and Constantin, Bernice, "Rapid assessment for a new invasive species threat: the case of the Gambian giant pouched rat in Florida" (2006). USDA National Wildlife Research Center - Staff Publications. 418.

https://digitalcommons.unl.edu/icwdm_usdanwrc/418

This Article is brought to you for free and open access by the U.S. Department of Agriculture: Animal and Plant Health Inspection Service at DigitalCommons@University of Nebraska - Lincoln. It has been accepted for inclusion in USDA National Wildlife Research Center - Staff Publications by an authorized administrator of DigitalCommons@University of Nebraska - Lincoln. 


\section{Authors}

Richard M. Engeman, John W. Woolard, Neil D. Perry, Gary W. Witmer, Scott Hardin, Lawrence Brashears, Henry Smith, Britta Muiznieks, and Bernice Constantin 


\title{
Rapid assessment for a new invasive species threat: the case of the Gambian giant pouched rat in Florida
}

\author{
Richard Engeman ${ }^{\mathrm{A}, \mathrm{G}}$, John W. Woolard ${ }^{\mathrm{B}}$, Neil D. Perry ${ }^{\mathrm{C}}$, Gary Witmer ${ }^{\mathrm{A}}$, Scott Hardin ${ }^{\mathrm{D}}$, \\ Lawrence Brashears $^{\mathrm{B}}$, Henry Smith ${ }^{\mathrm{E}}$, Britta Muiznieks ${ }^{\mathrm{F}}$ and Bernice Constantin ${ }^{\mathrm{B}}$ \\ ANational Wildlife Research Center, 4101 LaPorte Ave., Fort Collins, CO 80521-2154, USA. \\ ${ }^{B}$ USDA/Wildlife Services, 2820 East University Avenue, Gainesville, FL 32641, USA. \\ ${ }^{C}$ Department of Wildlife and Fisheries Science, Texas A\&M University, College Station, TX 77843, USA. \\ DFlorida Fish and Wildlife Conservation Commission, 620 South Meridian Street, Tallahassee, FL 32399, USA.

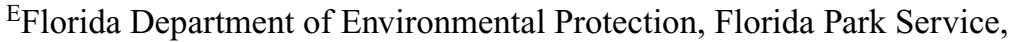 \\ 13798 S.E. Federal Highway, Hobe Sound, FL 33455, USA. \\ FUS Fish and Wildlife Service, PO Box 370, Key Largo, FL 33037, USA. \\ ${ }^{\mathrm{G}}$ Corresponding author. Email: richard.m.engeman@aphis.usda.gov
}

\begin{abstract}
The Gambian giant pouched rat (Cricetomys gambianus) is a large rodent that has established a breeding population in the Florida Keys. Should it successfully disperse to mainland Florida, it could continue spreading through much of North America where significant negative ecological and agricultural consequences could result. We rapidly developed the information for implementing an efficient and successful eradication program before dispersal to the mainland occurs. This included development of monitoring and indexing methods and their application to define the animal's range, the development of baits attractive to Gambian giant pouched rats, efficacy testing of toxicants, and development of bait-delivery devices that exclude native animals. Gambian giant pouched rats appeared confined to the western two-thirds of Grassy Key, but have dispersed across a soil-filled causeway west to Crawl Key. We identified preferred habitat characteristics and potential dispersal pathways. We developed photographic and tracking tile methods for detecting and indexing Gambian giant pouched rats, both of which work well in the face of high densities of non-target species. We identified a commercial anticoagulant bait and we developed a zinc phosphide (an acute toxicant) bait matrix that were well accepted and effective for controlling Gambian giant pouched rats. We also developed a bait station for delivering toxic bait to Gambian giant pouched rats without risk to native species. We consider that the criteria are met for a successful eradication to commence.
\end{abstract}

\section{Introduction}

Florida, along with Hawaii, has the most severe invasive species problems in the United States (USA Congress 1993), with breeding populations of new vertebrate species regularly identified. The negative impacts inflicted by exotic species on native species and ecosystems might be exceeded only by human-caused habitat destruction (Wilcove et al. 1998; Parker et al. 1999). The impacts from many introduced species are unknown or not readily perceived by the public. Realisation of an introduced species' existence and perhaps even its potential for severe impacts may not occur until after the species has been established for some time. Such was the case with the Gambian giant pouched rat (Cricetomys gambianus) in Florida.

About 1999, eight Gambian giant pouched rats escaped from an exotic pet breeder on Grassy Key, Florida (Perry et al. 2006). Wildlife management agencies were not aware of this release, or of the sightings by local residents. The Florida population was brought to the attention of authorities after media attention associated Gambian giant pouched rats in the USA pet trade with an outbreak of monkeypox in persons exposed to infected Gambian giant pouched rats and prairie dogs (Cynomys leucurus or C. ludovicianus) (Centers for Disease Control 2003). Subsequently, a local resident informed the USA Fish and Wildlife Service in spring 2004 of sightings of Gambian giant pouched rats, and area residents have since reported such sightings with increasing frequency (Epperson 2005; Grassy Key residents, pers. comm.). The presence of a breeding population of Gambian giant pouched rats on Grassy Key was confirmed in August of 2004 (Perry et al. 2006). Unconfirmed sightings suggested possible dispersal to other Keys, possibly as far northeast as Key Largo, the last island in the chain of Keys before the mainland.

Gambian giant pouched rats have the potential to become a highly destructive exotic species, particularly in agriculture. They are among the largest members of the rodent family Muridae, with males achieving weights as high as 
$2.8 \mathrm{~kg}$ (Rosevear 1969). They are omnivorous, consuming a variety of vegetables and fruits, insects, crabs and snails (Ajayi 1975; Smithers 1983; Fiedler 1988, 1994). They are also highly fecund, with gestation times of 27-42 days and 4-5 litters per year of 1-5 offspring (Rosevear 1969; Ajayi 1975; Hayssen et al. 1993). In an African agricultural setting, 42 Gambian giant pouched rats were removed from a 0.2-ha field of young peas in Zimbabwe (Smithers 1983; Fiedler 1994). Besides monkeypox, species of Cricetomys have been linked to potentially pathogenic zoonoses such as leptospirosis, bartonellosis, murine typhus, Q-fever and trypanasomiasis (Gretillat et al. 1981; Fiedler 1988; Hutin et al. 2001; Herder et al. 2002; Machang'u et al. 2004),

Its large size, high fecundity, omnivorous diet, and potential as vectors of serious diseases make this species an immediate threat to the indigenous ecological communities within the Florida Keys. Moreover, recent ecological modelling demonstrated that Gambian giant pouched rats could invade and establish viable populations throughout peninsular Florida, the USA Gulf Coast, and beyond to Central America (Peterson et. al. 2006). Wider areas of North America were also shown to be vulnerable to establishment of populations of Gambian giant pouched rats at lesser probabilities. Thus, the species must be viewed as a broad threat to colonise mainland North America.

Once a species has been deemed sufficiently threatening to warrant eradication, much information is needed to produce an efficient, effective and environmentally responsible control plan. The objectives of our study were to rapidly gather information, and develop and test methods for eradicating Gambian giant pouched rats from the Florida Keys. Our approach to rapid development of information may be useful for addressing incipient populations of other invasive species.

\section{Methods}

We sought to generate information in five areas essential for commencing an eradication program: distribution; habitat preferences; methods to detect and monitor populations; influence of non-target species on detection and management; and development of control methods. We used trapping, track and camera indices, radio-telemetry, and direct observations of live and road-killed animals to collect this information (Table 1). The US Department of Agriculture/Wildlife Services (WS) is the Federal agency responsible for managing conflicts with wildlife (US Department of Agriculture/Animal and Plant Health Inspection Service, US Department of Agriculture/Forest Service and Department of Interior/Bureau of Land Management 1997). Wildlife Services uses only approved and humane methods, and euthanasia procedures conformed to the guidelines of the American Veterinary Medical Association Panel on Euthanasia (American Veterinary Medical Association 2001) and set forth as agency policy in USDA/APHIS/WS Directive 2.505.

\section{Trapping}

Trapping was applied to address several of the above needs. We wanted to: (1) apply and refine trapping as a possible control tool for use in eradication, (2) evaluate its impacts to and from non-target species,
(3) detect the presence of Gambian giant pouched rats, and (4) refine the information on their distribution. We sampled Grassy, Vaca, Long, Duck, and Plantation Keys, and Curry Hammock State Park (Fig. 1, site descriptions in Table 1). Trapping was conducted in two phases. The first phase (30 January - 4 February 2005) focused on trapping Grassy Key, and expanded south to include state lands on Vaca Key (including Marathon International Airport) and in Curry Hammock State Park. The second phase (22 February - 19 March 2005) continued trapping on Grassy Key and expanded the efforts north to include Long Key, Duck Key, and Plantation Key (Fig. 1). Trapping on the keys other than Grassy Key represented exploratory efforts to determine whether Gambian giant pouched rats had dispersed to other islands. Trapping on Grassy Key was conducted at the sites (Table 1) labelled as Brobyn Hammock, Mitchell Hammock, Orange Street East, and Orange Street West (where Gambian giant pouched rats originally escaped). We conducted a total of 684 trap-nights using Tomahawk ${ }^{\circledR}$ cage traps (Tomahawk Live Trap Co., Tomahawk, Wisconsin) with $25 \times 25 \mathrm{~cm}$ entrances and baited with combinations of peanut butter, oats and corn. Trap sites were recorded with GPS units. Traps were set in the afternoon and checked the next morning.

\section{Developing detection methodology applicable to monitoring/indexing}

We investigated tracking tiles and motion-triggered digital cameras as potential methods that could be used for assessing distribution and control efficacy. In particular, we wanted the methods to produce suitable data for applying the general procedures for indexing animal populations outlined by Engeman (2005). We also evaluated these methods for simultaneously monitoring populations of non-target species, as this would provide valuable information for assessing and reducing nontarget hazards from methods for controlling Gambian giant pouched rats, and for reducing non-target interference with technologies for controlling Gambian giant pouched rats.

We tested a variety of track plate materials and marker-placement designs during 9-14 March 2005 to find the most useful combination from which index data might be obtained for the circumstances in the Florida Keys. Ink was a non-drying rubber-based ink, diluted with mineral oil. Track plate materials and ink-placement patterns were adjusted according to outcomes. We sequentially evaluated the materials for use as track plates: $30 \times 30 \mathrm{~cm}$ linoleum tiles, $60 \times 60 \mathrm{~cm}$ white acrylic panels (used to cover fluorescent ceiling lights), and $41 \times 41 \times$ $1.25 \mathrm{~cm}$ Styrofoam insulation sheets. Ink-placement patterns were applied with a $5-\mathrm{cm}$ roller. The inking patterns we considered included (in sequential order): one-roller-width perimeter of ink around the edge of the plate, a one-roller-width of ink on two opposite sides of the plate, and a one-roller-width band of ink was placed diagonally across the plate. In each design the same attractant as used for trapping was placed in the centre of the plate.

We initially tested photography as a monitoring method using a motion-triggered digital camera (Cuddeback ${ }^{\circledR}$, Non Typical Inc., Park Falls, Wisconsin) for a five-night trial (also 9-14 March 2005). The first two nights the camera targeted the base of a tree, which had been baited with peanut butter and fish oil. We then moved the camera $\sim 40 \mathrm{~m}$ eastnorth-east for the remaining three nights and baited with a viscous combination of mineral oil and peanut butter spread over the bottom $60 \mathrm{~cm}$ of a tree base. Date and time of photos were recorded with the images.

\section{Tracking tile applications}

After selecting the best tile and ink pattern, we operationally applied 36 track-plate-nights during 15-16 March 2005 with Styrofoam plates on Grassy Key in the Mitchell Hammock and Orange Street East sites (Table 1). An additional 36 plate-nights were applied to the Long Key Transfer Station. This site is where all refuse and brush piles collected by the county Waste Management division on Grassy Key are delivered and reloaded onto bigger trailers for shipment to Pompano Beach on the 
Florida mainland, creating a possible transport mechanism for emigration of Gambian giant pouched rats. Track plates were photographed each morning for later evaluation and measurement. They were replaced with a fresh plate and checked for a second consecutive day.

\section{Application of cameras for indexing}

Following development and testing of camera-station methodology, cameras were operationally placed to index populations of Gambian giant pouched rats and non-target species within seven potential habitat areas on Grassy Key (Table 1). Outside of Grassy Key, camera surveys were also placed in locations where Gambian giant pouched rats were deemed most likely to occur, on the basis of their proximity to Grassy Key, transportation pathways, and reported sightings. Camera indexing stations were set up on Long Key (in addition to trapping and track plates). We surveyed Crawl Key and keys in Curry Hammock State Park, because they are serially connected to Grassy Key's west end by soil-filled causeways (Table 1), and unconfirmed sightings of Gambian giant pouched rats had come from these areas.

On the basis of the results from the initial camera test, the number of intrusions into the photographic space was used as the observation variable for non-target species in the same manner that intrusions to passive tracking plots have been used (Engeman et al. 2000). Sufficiently distinctive pelage among Gambian giant pouched rats allowed the number of unique individuals photographed each day to be used in analyses, rather than the number of intrusions into the camera space by a species (as had to be done for non-target species). Both the daily number of individual Gambian giant pouched rats and the daily number of intrusion measurements provided appropriate data structures for calculating abundance indices (AI) at each site according to the analytical methods outlined in Engeman (2005), and as applied for passive tracking indices (e.g. Engeman et al. 2000, 2003). A linear model incorporating random effects described measurements at each camera station each day, with no assumptions of independence among stations or days. The mean measurement across stations was calculated for each day. The index values were the means of the daily means:

$$
A I=\frac{1}{d} \sum_{j=1}^{d} \frac{1}{s_{j}} \sum_{i=1}^{s_{j}} x_{i j},
$$

where $x_{\mathrm{ij}}$ represents the number of individuals (Gambian giant pouched rats) or number of visits (non-target species) at the $i$ th camera station on the $j$ th day, $d$ is the number of days of observation, and $s_{\mathrm{j}}$ is the number of stations contributing data on the $j$ th day. SAS PROC VARCOMP, using restricted maximum-likelihood estimation (REML) (SAS Institute 1996) was used to calculate the variance components (Searle et al. 1992) needed in the variance-estimation formula (Engeman 2005).

Cameras were used to collect data on Gambian giant pouched rats and non-target species during eight periods from June through July

Table 1. Description of the areas surveyed for Gambian giant pouched rats by camera indexing procedures, tracking plates, and trapping Sites are presented in an approximate east (nearest the mainland) to west (most remote) order. Habitat descriptions are from Florida Natural Areas Inventory (FNAI 1990)

\begin{tabular}{|c|c|c|}
\hline Survey area & Description of location and habitat & Observation methods \\
\hline Plantation Key & $\begin{array}{l}\text { Over } 40 \mathrm{~km} \text { north-east of Grassy Key, separated by numerous bridges over salt water. This key } \\
\text { has substantial rockland hammock habitat and was surveyed in response to unconfirmed } \\
\text { sighting of Gambian giant pouched rats. }\end{array}$ & Trapping \\
\hline $\begin{array}{l}\text { Long Key transfer } \\
\text { station }\end{array}$ & $\begin{array}{l}\text { Located } \sim 12.5 \mathrm{~km} \text { north-east of Grassy Key, separated by bridges over salt water. The Long } \\
\text { Key transfer station receives trash from Grassy Key and other keys for loading to larger } \\
\text { trucks and shipment to the mainland landfill. }\end{array}$ & $\begin{array}{l}\text { Trapping, track plates, } \\
\text { night vision }\end{array}$ \\
\hline Duck Key & $\begin{array}{l}\text { Densely populated island of former rockland hammock habitat, separated from the eastern end } \\
\text { of Grassy Key by short bridges }(2 \mathrm{~km}) \text { over salt water. }\end{array}$ & Trapping \\
\hline $\begin{array}{l}\text { Grassy Key, Mitchell } \\
\text { Hammock }\end{array}$ & $\begin{array}{l}\text { Undeveloped area in the north-east portion of Grassy Key, largely comprising rockland } \\
\text { hammock habitat, but separated from similar habitat areas to the west by a saltwater bay. }\end{array}$ & Track plates, cameras \\
\hline $\begin{array}{l}\text { Grassy Key, Aqua- } \\
\text { culture Center }\end{array}$ & $\begin{array}{l}\text { Undeveloped area on the south-east shoreline (one dwelling), comprising primarily mangroves } \\
\text { with some rockland hammock habitat that might support Gambian giant pouched rats. }\end{array}$ & Cameras \\
\hline $\begin{array}{l}\text { Grassy Key, Button- } \\
\text { wood forest }\end{array}$ & $\begin{array}{l}\text { West of the aquaculture centre, south of Highway } 1 \text {. Buttonwood forest on coastal berm habitat } \\
\text { probably marginal for Gambian giant pouched rats. }\end{array}$ & Cameras \\
\hline $\begin{array}{l}\text { Grassy Key, } \\
\text { Crain Street }\end{array}$ & North across Highway 1 from buttonwood forest. Undeveloped rockland hammock habitat. & Cameras \\
\hline $\begin{array}{l}\text { Grassy Key, Orange } \\
\text { Street East }\end{array}$ & $\begin{array}{l}\text { Centrally located north of Crain Street site and east of Orange Street. Rockland hammock } \\
\text { habitat developed into a residential area. }\end{array}$ & Track plates, cameras \\
\hline $\begin{array}{l}\text { Grassy Key, Orange } \\
\text { Street West }\end{array}$ & $\begin{array}{l}\text { Located west of Orange Street in same rockland hammock band as Orange Street east. Also } \\
\text { developed into residential area. Gambian giant pouched rats were originally introduced to } \\
\text { this site. }\end{array}$ & Cameras \\
\hline $\begin{array}{l}\text { Grassy Key, Brobyn } \\
\text { Hammock }\end{array}$ & West of Orange Street west site in the same band of rockland hammock, but undeveloped. & Cameras \\
\hline Crawl Key & $\begin{array}{l}\text { Formerly separate island at west end of Grassy Key, but connected by a } 30-40 \text {-m-wide filled } \\
\text { causeway for Highway } 1 \text {. Undeveloped and comprising rockland hammock habitat. }\end{array}$ & Cameras \\
\hline $\begin{array}{l}\text { Curry Hammock } \\
\text { State Park }\end{array}$ & $\begin{array}{l}\text { West of Crawl Key, several small keys now connected by soil-filled causeways for Highway } 1 . \\
\text { Undeveloped rockland hammock habitat. }\end{array}$ & Trapping, cameras \\
\hline Vaca Key & $\begin{array}{l}\text { Highly developed former rockland hammock habitat into residential, commercial and airport } \\
\text { areas. Separated by short bridges over saltwater and soil-filled causeways from Curry } \\
\text { Hammock State Park. Surveyed in response to unconfirmed sightings of Gambian giant } \\
\text { pouched rats. }\end{array}$ & Trapping \\
\hline Knights Key & $\begin{array}{l}\text { Little key } 16.8 \mathrm{~km} \text { west of Vaca Key, separated by a soil-filled causeway. Location where } \\
\text { debris from Hurricane Wilma collected and piled before transport to mainland landfills. }\end{array}$ & Cameras \\
\hline
\end{tabular}




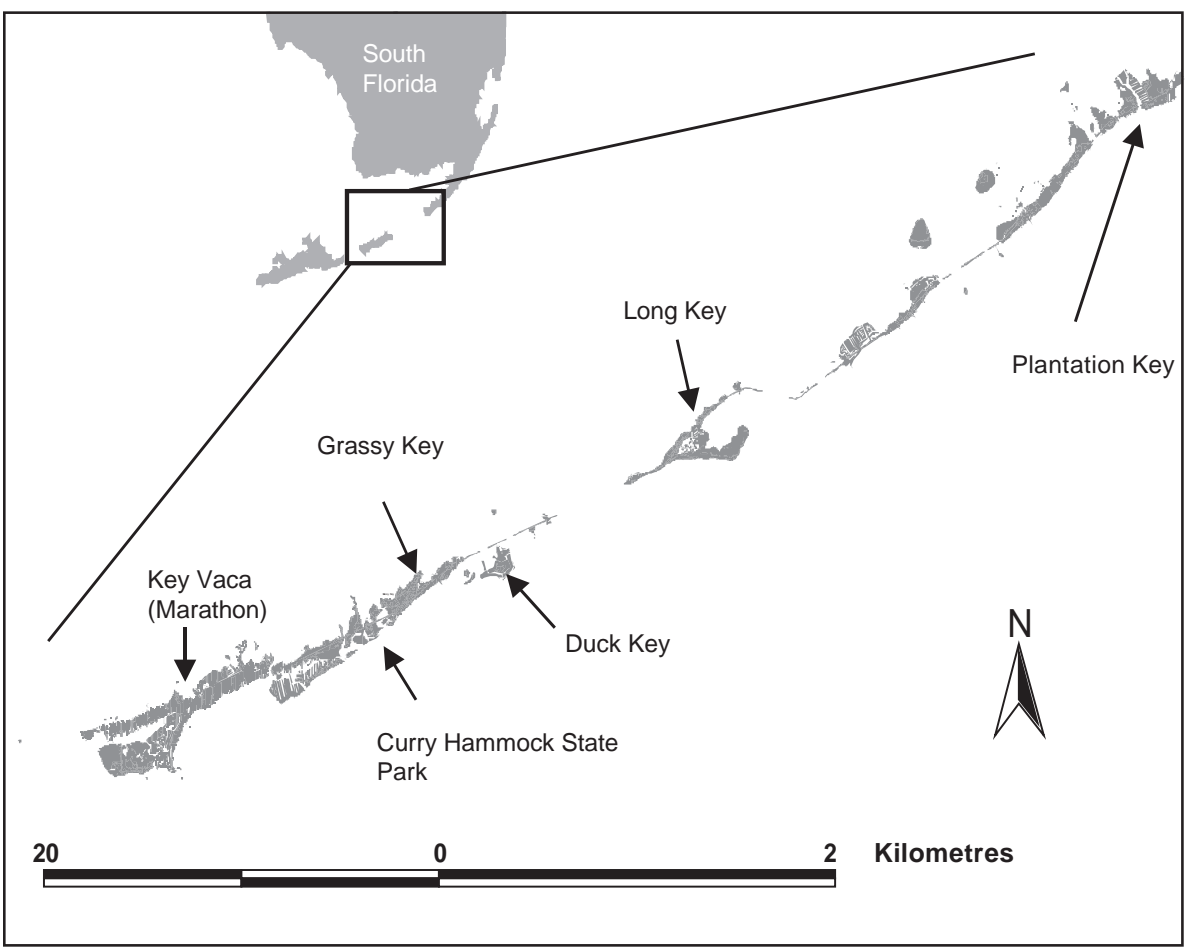

Fig. 1. Study area for Gambian giant pouched rats in the Florida Keys.
2005 (Tables 1 and 2). Photographic data were collected on consecutive days from each camera for the life of the battery, after which data were retrieved and the batteries recharged for the next monitoring period. Four or more consecutive days of data were typically collected. The flexibility of the index formula accepts unequal numbers of cameras to provide data each day, so the amount of viable data collected from one camera was not limited by the battery life of other cameras used.

The highly destructive Hurricane Wilma struck the Florida Keys in October 2005. Much of Grassy Key was inundated by more than $1 \mathrm{~m}$ of salt water from the storm surge, with only the higher portions of US Highway 1 escaping inundation. The consequences of the storm presented a variety of impacts, as well as opportunities for dispersal of Gambian giant pouched rats from Grassy Key. First, the storm surge may have reduced populations directly by drowning, or indirectly by reducing vegetative food sources. On the other hand, the cleanup of the enormous amount of debris offered another transport mechanism off Grassy Key. Therefore, follow-up camera surveys were instituted during the last week of November 2005 to see whether populations still remained at the two sites on Grassy Key previously having the highest indices of Gambian giant pouched rats. Five cameras were placed for one night at the Orange Street East site and one camera was placed in the escape site at Orange Street West. Six cameras were also placed for two nights on Knights Key (Table 1) where hurricane debris was collected and mounded before removal from the Keys.

\section{Additional observations}

We experimented with several other observation methods. Because of the pathway that the Long Key Transfer Station poses for dispersal to the mainland, we also surveyed it for three consecutive nights using Generation-3 night-vision equipment (PVS7 Delta, Litton Industries, Woodland Hills, California) with a 6 million candle-power infrared light for non-intrusive illumination. We focused on food source piles and baits (non-toxic) where rats would likely feed.

We conducted a pilot radio-telemetry study during Phase 1 of trapping on Grassy Key where we monitored movements of two Gambian giant pouched rats. One male and one female were trapped and fitted with 23-g Advanced Telemetry Systems Inc. (Isanti, Minnesota) radio-

Table 2. Trapping success from two phases of trapping for Gambian giant pouched rats in the Florida Keys Phase 1: 30 January - 4 February 2005; Phase 2: 22 February - 19 March 2005

\begin{tabular}{lccccccc}
\hline Island & Phase & Trap-nights & \multicolumn{5}{c}{ No of. animals captured } \\
& & & $\begin{array}{c}\text { Gambian giant } \\
\text { pouched rats }\end{array}$ & Raccoons & Opossums & Black rats & Feral cats \\
\hline Grassy Key & 1 & 199 & 14 & 64 & 33 & 4 & 1 \\
& 2 & 277 & 15 & 36 & 23 & 6 & 0 \\
Curry Hammock & 1 & 476 & 29 & 100 & 56 & 10 & 1 \\
Vaca Key & 1 & 168 & 0 & 11 & 2 & 0 & 0 \\
Duck Key & 2 & 108 & 0 & 86 & 3 & 1 & 1 \\
Long Key & 2 & 117 & 0 & 8 & 16 & 11 & 0 \\
Plantation Key & 2 & 88 & 0 & 16 & 2 & 11 & 0 \\
\hline
\end{tabular}


transmitters on neoprene collars. The animals were released at the site of capture and their movements recorded for two weeks.

We also opportunistically inspected road-killed animals as another means to monitor the distribution of Gambian giant pouched rat, although we did not have the resources to conduct regular (e.g. daily), extensive and systematically designed surveys of the highway and road systems on the keys.

\section{Toxicant bait testing}

Using the trapping and camera information on locations where Gambian giant pouched rats were abundant, we captured animals to evaluate bait acceptance and efficacy. To rapidly focus on efficacious and well accepted baits, trials followed a three-step process, beginning with four-choice tests where four rats were simultaneously presented with four different anticoagulant baits: Ramik $^{\circledR}$ mini-bars $(0.005 \%$ diphacinone, first-generation anticoagulant), Contrac ${ }^{\circledR}(0.005 \%$ bromadiolone, second-generation anticoagulant), Havoc ${ }^{\circledR}(0.005 \%$ brodifacoum, second-generation anticoagulant), and d-Con ${ }^{\mathbb{B}}(0.0025 \%$ difethialone, second-generation anticoagulant). Step 2 was a twochoice test where four rats were simultaneously presented with the Ramik (diphacinone) mini-bars and untreated horse sweet mix as a control. Step 3 was another two-choice test, but where nine rats were simultaneously presented with $1.6-2.0 \%$ zinc phosphide (ZP), an acute toxicant, in a matrix of peanut butter and horse sweet mix (corn, oats, molasses) and untreated horse sweet mix as an alternative food.

A commercial bait station (Protecta ${ }^{\circledR}$, Bell Laboratories Inc., Madison, Wisconsin) and a custom-designed bait station made of PVC pipe (Fig. 2) were tested using untreated bait to determine bait accessibility for Gambian giant pouched rats, and exclusion of native species. Cameras were used to monitor the animals' responses.

\section{Results}

\section{Trapping}

We trapped 29 Gambian giant pouched rats during Phases 1 and 2 of trapping, all on Grassy Key (Table 2). Relative to the numbers of Gambian giant pouched rats captured, large numbers of non-target animals were captured (Table 2), most notably raccoons (Procyon lotor), but also Virginia opos-

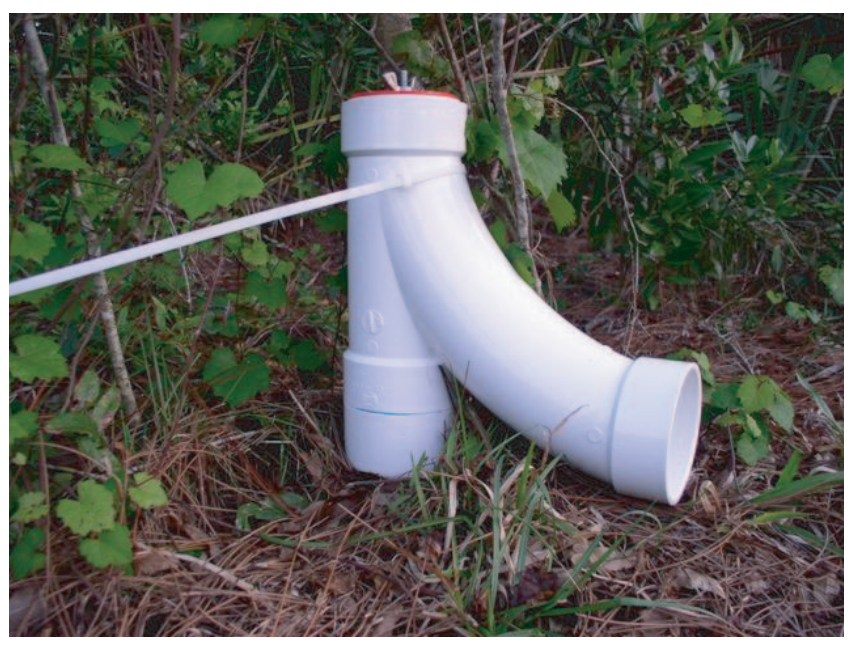

Fig. 2. Custom-designed bait station for delivering baits to Gambian giant pouched rats in the Florida Keys while excluding native species. Bait is accessed and placed in the 'heel' of the boot-shaped design through the locking lid on top. (Photograph by J. Woolard.) sums (Didelphis virginiana), black rats (Rattus rattus), and the occasional feral cat (Felis catus). Overall, more than three times as many raccoons and twice as many opossums as Gambian giant pouched rats were captured on Grassy Key. About five and a half times as many non-target animals were captured as Gambian giant pouched rats. Thus, non-target trap saturation undoubtedly impaired the efficiency of trapping Gambian giant pouched rats. Gambian giant pouched rats were not captured in traps that previously captured raccoons, which could be an important consideration for future trapping efforts. Previous capture of a Gambian giant pouched rat did not appear to affect results.

\section{Track plate trials and applications}

Tracks of Gambian giant pouched rats were distinctive from all other animal species present. The linoleum tiles were too small for the size of animals tracking them, while the acrylic panels were too brittle. Ink on all four sides of a plate resulted in track saturation that made identification impossible. Ink along two edges allowed some animals to visit (attractant removed) without leaving tracks. The best combination of track plate materials and inking pattern for detecting Gambian giant pouched rats in the face of the saturating impacts from non-target species was the $41 \times 41 \mathrm{~cm}$ Styrofoam plates with ink applied diagonally across the plate. Thus, this was the track plate methodology applied operationally for detecting Gambian giant pouched rats.

Operationally, track plates recorded activity of Gambian giant pouched rats in 4 of 36 plate-nights, with all recorded at the Orange Street East site on Grassy Key where trapping had already confirmed the presence of Gambian giant pouched rats. By comparison, 14 and 18 plate-nights recorded raccoons and black rats, respectively. No tracks of Gambian giant pouched rats were observed at the Long Key Transfer Station, but raccoons, opossums, black rats, and feral cats were detected on 14, 5, 1 and 4 of 36 plate-nights, respectively, confirming the trapping results of large numbers of non-target species.

\section{Camera trials and survey results}

The trial camera observations were made within known Gambian giant pouched rat areas, and recorded 56 animal observations. Three Gambian giant pouched rats were recorded over the combined five nights at the two locations, while 37 raccoon, 9 opossum and 7 black rat visits were recorded, further evidence of high non-target densities. In all, 39 of $56(70 \%)$ animal photos were recorded during the first nights of each camera session. All photos were clear and none contained an unidentifiable animal. The ability to detect black rats reveals the potential for detecting juvenile Gambian giant pouched rats. The distal half of the tail on Gambian giant pouched rats is creamy white, making them easily distinguished from black rats. The first Gambian giant pouched rat photographed was the 23 rd visit to the bait. 
Applications of cameras to collect data for calculating indices across space and time yielded the results in Table 3. Gambian giant pouched rats were observed only in higher drier rockland hammock habitat (Florida Natural Areas Inventory (FNAI) 1990), especially where the habitat has been modified and developed into residential areas (Table 1). Gambian giant pouched rats were found in the band of this habitat extending east and west from the site where the escape took place (Tables 1,3). Gambian giant pouched rats were not observed in similar, apparently suitable, habitats on eastern Grassy Key. However, Gambian giant pouched rats were observed on Crawl Key immediately west of Grassy Key, demonstrating that the soil-filled causeways can be used for dispersal to new locations. The small Keys of Curry Hammock State Park and Vaca Key are also connected by causeways west from Crawl Key, but we did not observe Gambian giant pouched rats at these sites, although there have been unconfirmed reports in these areas. Survival of Gambian giant pouched rats through Hurricane Wilma was demonstrated at the two sites on either side of Orange Street, but they were not detected on Knights Key where hurricane debris was accumulated for transfer to the mainland (Table 3).

\section{Radio-telemetry, road-kill and night-vision observations}

Each radio-collared animal was located three times. The female rat was tracked to a burrow system the day after release. She was detected $\sim 100 \mathrm{~m}$ from the burrow three days later and the collar was found near the previously located burrow entrance five days later. The neck circumference of the Gambian giant pouched rats is large relative to their skull, and she likely worked the collar off her neck. The male rat was found $920 \mathrm{~m}$ from the point of release the next day. Two later locations found him within $200 \mathrm{~m}$ of the first location. However, the collar signal deteriorated with each subsequent location. Three subsequent attempts to locate the male failed to detect a signal.

The only road-killed Gambian giant pouched rat was found during Phase 2 of trapping on Grassy Key. The surveillance at the Long Key transfer station using night-vision technology yielded no observations of Gambian giant pouched rats.

Table 3. Indexing results for Gambian giant pouched rats and non-target species using remote digital camera data The observation variable for Gambian giant pouched rats was the daily number of individuals photographed. Because individuals could not be distinguished for non-target species, the observation variable was the daily number of intrusions by each species. Sites with Gambian giant pouched rats are given in bold face. Observations made in November were to check Gambian giant pouched rat status in the aftermath of Hurricane Wilma

\begin{tabular}{|c|c|c|c|c|c|c|}
\hline Island & Grassy Key site & Time point & $\begin{array}{c}\text { Gambian giant } \\
\text { pouched rat }\end{array}$ & Raccoon & Opossum & Black rat \\
\hline \multirow[t]{21}{*}{ Grassy Key } & \multirow[t]{2}{*}{ Aqua-culture } & 22.vi.2005 & 0.000 & 2.000 & 0.000 & 0.000 \\
\hline & & 25.vii.2005 & 0.000 & 2.000 & 0.250 & 0.125 \\
\hline & \multirow[t]{2}{*}{ Brobyn Hammock } & 22.vi.2005 & 0.063 & 1.375 & 0.125 & 2.500 \\
\hline & & 25.vii.2005 & 0.000 & 2.688 & 0.188 & 0.000 \\
\hline & \multirow[t]{2}{*}{ Crain Street Hammock } & 30.vi.2005 & 0.000 & 2.000 & 0.000 & 0.000 \\
\hline & & 22.vii.2005 & 0.000 & 2.250 & 0.000 & 4.500 \\
\hline & \multirow[t]{2}{*}{ Buttonwood forest } & 30.vi.2005 & 0.000 & 1.000 & 0.000 & 0.000 \\
\hline & & 22.vii.2005 & 0.000 & 2.250 & 0.000 & 0.000 \\
\hline & \multirow[t]{3}{*}{ Mitchell Hammock } & 06.vii.2005 & 0.000 & 0.722 & 0.000 & 0.000 \\
\hline & & 14.vii.2005 & 0.000 & 0.700 & 0.000 & 0.000 \\
\hline & & 22.vii. 2005 & 0.000 & 1.000 & 0.000 & 0.056 \\
\hline & \multirow[t]{5}{*}{ Orange Street East } & 30.vi.2005 & 0.625 & 3.500 & 0.375 & 0.000 \\
\hline & & 06.vii.2005 & 0.000 & 2.000 & 0.333 & 0.000 \\
\hline & & 11.vii.2005 & 0.000 & 2.500 & 0.000 & 0.000 \\
\hline & & 25.vii.2005 & 0.313 & 1.875 & 0.313 & 0.000 \\
\hline & & 22.xi.2005 & 3.000 & 3.000 & 6.000 & 0.000 \\
\hline & \multirow[t]{5}{*}{ Orange Street West } & 28.vi.2005 & 1.263 & 2.500 & 0.775 & 1.063 \\
\hline & & 06.vii.2005 & 0.500 & 1.639 & 0.000 & 0.278 \\
\hline & & 11.vii.2005 & 0.357 & 1.786 & 0.000 & 0.571 \\
\hline & & 25.vii.2005 & 0.960 & 2.373 & 0.187 & 0.200 \\
\hline & & 22.xi.2005 & 1.600 & 8.800 & 0.800 & 1.600 \\
\hline \multirow[t]{2}{*}{ Crawl Key } & & 27.vi.2005 & 0.067 & 1.717 & 0.133 & 1.900 \\
\hline & & 22.vii.2005 & 0.360 & 0.821 & 0.107 & 0.821 \\
\hline \multirow[t]{3}{*}{ Curry Hammock } & & 06.vii.2005 & 0.000 & 1.167 & 0.000 & 0.000 \\
\hline & & 11.vii.2005 & 0.000 & 1.833 & 0.056 & 0.000 \\
\hline & & 22.vii.2005 & 0.000 & 2.333 & 0.000 & 0.083 \\
\hline \multirow[t]{2}{*}{ Long Key transfer station } & & 23.vi.2005 & 0.000 & 2.750 & 0.600 & 0.550 \\
\hline & & 26.vii.2005 & 0.000 & 3.375 & 0.063 & 0.500 \\
\hline Knights Key & & 21.xi.2005 & 0.000 & 2.085 & 0.000 & 0.000 \\
\hline
\end{tabular}




\section{Toxicant testing}

In Step 1, the Gambian giant pouched rats showed a preference in the four-choice tests for the Ramik mini-bars over the three second-generation anticoagulants baits, although some Contrac and Havoc were also consumed by all rats. Only two of four rats consumed d-Con. The average amounts consumed per animal were: Ramik mini-bars, 69 g; Havoc, $50.5 \mathrm{~g}$; Contrac, $37 \mathrm{~g}$; d-Con, $11.3 \mathrm{~g}$. In no case was all of the bait consumed. All four rats died within 5-7 days.

In the Step 2 two-choice tests, all rats fed on some of the Ramik mini-bars and all four rats died within 6-11 days. The average amount of Ramik mini-bars consumed was $183.5 \mathrm{~g}$. In no case was all of the bait consumed. All rats consumed only a small amount (averaging $19.5 \mathrm{~g}$ ) of the 'control' feed (horse sweet mix).

In the Step 3 two-choice tests, all rats consumed a small amount (7.3 g average) of the 1.6-2\% ZP bait and all nine rats died in $\leq 43 \mathrm{~h}$, seven dying in $<24 \mathrm{~h}$. Virtually no control horse sweet mix was eaten in this trial.

On the basis of these results, two rodenticide baits appear valuable for use on Gambian giant pouched rats: the firstgeneration anticoagulant, $0.005 \%$ diphacinone (Ramik minibars), and the acute $2 \%$ ZP bait (mixed with peanut butter and horse sweet mix). The Ramik bait would need to be presented for over a week to assure that a lethal dose is consumed, whereas, a small amount of the acute ZP bait consumed in a single feeding is lethal. Over 600 photographic observations of the PVC pipe bait station demonstrated delivery of bait to Gambian giant pouched rats while excluding native species. The commercial bait station excluded native species but also restricted adult Gambian giant pouched rats from access. Both Ramik mini-bars and the ZP baits could be delivered in PVC pipe bait stations.

\section{Discussion}

The introduction of a highly fecund and potentially destructive exotic species, such as the Gambian giant pouched rat, coupled with potential pathways for dispersal, merits a rapid response. A single pregnant female could start a new colony. Our study has shown that in a relatively short time sufficient information can be obtained to plan an eradication. We found Gambian giant pouched rats common in developed areas of Grassy Key, and we identified their habitat preferences. We also found that sympatric populations of non-target species, especially raccoons, exist in great abundance and could saturate improperly configured control and monitoring devices intended for Gambian giant pouched rats. Control devices must exclude non-target species, and monitoring devices should be able to accommodate many non-target visits and still be able to detect Gambian giant pouched rats.

Gambian giant pouched rats were common in the rockland hammock habitat of central Grassy Key. They do not appear to inhabit wet shrub and mangrove habitats.
Gambian giant pouched rats probably do not need to create their own burrows in the keys because limestone formations, exposed shrub/tree root systems, human dwellings, and debris piles offer ample substitutes. Gambian giant pouched rats fare well in proximity to humans. There are anecdotal reports from residents, who have observed them feeding on pet food placed outdoors, with cats having been observed to avoid Gambian giant pouched rats feeding from their food bowls.

We detected no Gambian giant pouched rats outside of Grassy Key and adjoining Crawl Key, although they could emigrate by many vectors at any time. Although the Duck Key Bridge $(\sim 1.9 \mathrm{~km})$ could be a barrier, the telemetered male traveled almost $1 \mathrm{~km}$ in a night. Therefore, the bridge should not be discounted as an emigration pathway. Education of Grassy Key residents might help prevent stowaways on vehicles. Although we did not observe Gambian giant pouched rats at the Long Key Transfer Station and hurricane cleanup sites, they provide obvious means for enabling Gambian giant pouched rats to reach the mainland. Therefore, these sites should be monitored, as should trash receiving sites on the mainland. Emigration south-west along US Highway 1 is a strong probability, because soilfilled causeways and one small bridge are the only barriers to nearby keys, and our data demonstrated such dispersal from Grassy Key to Crawl Key. A temporally and geographically systematic survey of the highway should be part of future monitoring. Keys where probable sightings are reported should be more thoroughly examined with designed surveys of secondary roads.

Rapid means to detect and survey Gambian giant pouched rats is essential for monitoring distribution and relative abundance, evaluating efficacy of removal techniques, and detecting their presence at new sites. Such methodology might permit optimisation of timing and placement of control devices in the same fashion that greatly improved efficacy and efficiency elsewhere (Engeman et al. 2003, 2005). Motion-triggered digital cameras served well to detect Gambian giant pouched rats while providing data suitable for monitoring abundance. Digital cameras offer the capability to record a large number of visits, and batteries usually lasted $>4$ days. Their ability to record Gambian giant pouched rats is not hindered by saturation by non-target species at camera stations. Also, because sites holding Gambian giant pouched rats did not always yield observations of Gambian giant pouched rats on each sampling occasion, surveys in suitable habitats in the most vulnerable areas should be repeated regularly. We found the combination of mineral oil and peanut butter to provide an effective attractant for three nights, although it is preferable from an efficacy, and also from an analytical, standpoint to replenish the attractant after each night. One limiting factor for cameras (outside of cost) is to situate them so the chance of theft or vandalism is minimised. Hence, cameras may not be suitable for all sites. 
Tracking methods, which are economical but more labour intensive than cameras, would complement cameras in those instances. Tracking indices also have been highly successful for indexing many species (e.g. Engeman et al. 2000, 2001, 2005), including rodents (Engeman 2005; Engeman and Whisson 2006).

On the basis of the management of introduced mammals in New Zealand, Parkes and Murphy (2003) delineated some of the 'obligate rules' for successful eradication: (1) all individuals of the target species must be at risk of being killed, (2) target species must be removed at a rate greater than the rate at which they replace their losses, and (3) the risk of immigration must be zero. If we assume that no other persons in the keys are maintaining populations of Gambian giant pouched rats (that might be released or escape), and if persons abide by the relatively new federal regulation making it illegal to bring Gambian giant pouched rats into the US, the last rule is met. The rodenticide efficacy trials suggest that Rules 1 and 2 can be met with a thoroughly planned and implemented bait-station program.

The success of a rodenticide baiting program requires: (1) an efficacious and palatable bait, which we have in the acute ZP and the diphacinone (Ramik mini-bars) baits; (2) an effective delivery system accessible by all Gambian giant pouched rats while excluding native animals, also available; (3) monitoring of Gambian giant pouched rats, possible by multiple methods of which remote cameras are the most effective and efficient; (4) the support and cooperation by federal and state agencies, private companies, the public and, importantly, private landowners, because access to lands occupied by Gambian giant pouched rats is essential for eradication. A public relations effort has been initiated in the Florida Keys by distributing a pamphlet describing the situation, placing general information on the Florida Fish and Wildlife Conservation Commission website (www.wld.fwc.state.fl.us/critters/exotics/exotics.asp), and by providing a reporting page on the same website (www.myfwc.com/Exotic/rat/).

Our data show the ZP bait to be readily accepted with only minimal consumption required for a lethal dose, thereby increasing the likelihood that a lethal dose would be consumed at the bait station. Thus, we feel the acute ZP bait applied in 10-day pulses followed by monitoring would optimise human and material resources while leading to successful eradication. Prebaiting using the same bait matrix without the toxicant is often done and often recommended on the labels for ZP baits to help prevent 'bait-shyness' whereby animals become somewhat sick from a sublethal dose, and decline to eat that bait again (for a review, see Salmon et al. 2000). Even though our ZP bait seems very acceptable/palatable to Gambian giant pouched rats, a conservative approach would be to apply prebait. In the absence of experience with Gambian giant pouched rats, a conservative spacing for a bait station grid probably would be no greater than $50 \times$
$50 \mathrm{~m}$, and in areas where human-sources may reduce the need for foraging movements, the grid spacing probably should not exceed $40 \times 40 \mathrm{~m}$.

Whereas application of ZP baits in the specially designed stations could form the basis for eradication on Grassy and Crawl Keys, trapping should probably be employed if Gambian giant pouched rats were discovered on keys within the range of an endangered rodent, such as the Key Largo woodrat (Neotoma floridana smalli). Live traps allow the safe release of non-target species. However, high capture rates of non-target species (raccoons, opossums, roof rats) would greatly reduce efficiency of eradication efforts, with our data showing that the repellent effect from previously trapped predators would compound the inefficiency. A similar effect was documented in Hawaii where black rats avoided traps that had previously captured mongooses (Tobin et al. 1994). Nonetheless, cage traps have been used successfully to eradicate black rats from a small ( $\sim 6.1 \mathrm{ha})$ island in the USA Virgin Islands (J. Rebholtz, personal communication) while reducing risks to endangered St Croix ground lizards (Ameiva polpos).

The information developed here could serve as a model for preparing control or eradication efforts for other potentially destructive invasive species. This is especially true in Florida, which often serves as the gateway to North America for non-native introductions (USA Congress 1993). Some invasive species have the potential for significant ecological or agricultural harm, but little information is available upon which to base control or eradication. Two prominent examples are the Nile monitor (Varanus niloticus), a large, prolific lizard that is well established in Cape Coral (Enge et al. 2004), and the Burmese python (Python molurus bivittatus), now found throughout the southern tip of Florida (Meshaka et al. 2004; Snow and Oberhofer 2004). Both species have demonstrated the ability to expand their range in Florida, have the potential to disperse in the southern USA, and present threats to native species, including threatened and endangered species (Western 1974; Enge et al. 2004). Control of these species should be viewed with urgency. However, information for their control is limited and we cannot find reports of either species being targeted for a control effort. Similar to the case of the Gambian giant pouched rat, the rapid development of detection, monitoring, and control methods could quickly lead to successful control or eradication procedures of these examples and other invasive species while a practical opportunity exists to contain and/or remove their populations.

\section{Acknowledgments}

Britta Hanson and Craig Okraska provided enthusiastic help and expertise. Darin Carroll of the Centers for Disease Control provided excellent insight into the Gambian giant pouched rat. Phil Frank, Dominique Watts, and Israel Parker 
of the National Key Deer Refuge provided logistical support and volunteered labour. Chris Bergh, Alison Higgins and Chuck Byrd of The Florida Keys Nature Conservancy contributed invaluable help in the field and persistent pressure to get this work started. Bruce Warburton of Landcare Research, New Zealand, advised on possible control methods. We thank the two referees for valuable suggestions that greatly improved this paper.

\section{References}

Ajayi, S. S. (1975). Observations on the biology, domestication, and reproductive performance of the african giant pouched rat Cricetomys gambianus (Waterhouse) in Nigeria. Mammalia 39, 344-364.

American Veterinary Medical Association (2001). 2000 Report of the AVMA Panel on Euthanasia. Journal of the American Veterinary Medical Association 218, 669-696. doi:10.2460/javma.2001. 218.669

Centers for Disease Control (2003). Multistate outbreak of monkeypox - Illinois, Indiana, Kansas, Missouri, Ohio, and Wisconsin, 2003 Morbidity and Mortality Weekly Report 52, 642-644.

Enge, K. M., Krysko, K. L., Hankins, K. R., Campbell, T. S., and King, F. W. (2004). Status of the Nile monitor (Varanus niloticus) in southwestern Florida. Southeastern Naturalist 3, 571-582. doi:10.1656/1528-7092(2004)003[0571:SOTNMV]2.0.CO;2

Engeman, R. M. (2005). A methodological and analytical paradigm for indexing animal populations applicable to many species and observation methods. Wildlife Research 32, 203-210. doi:10.1071/ WR03120

Engeman, R. M., and Whisson, D. A. (2006). Using a general indexing paradigm to monitor rodent populations. International Biodeterioration \& Biodegradation 58, 2-8.

Engeman, R. M., Pipas, M. J., Gruver, K. S., and Allen, L. (2000). Monitoring coyote populations with a passive activity index. Wildlife Research 27, 553-557. doi:10.1071/WR98090

Engeman, R. M., Constantin, B., Nelson, M., Woolard, J., and Bourassa, J. (2001). Monitoring changes in feral swine population and spatial distribution of activity. Environmental Conservation 28, 235-240.

Engeman, R. M., Martin, R. E., Constantin, B., Noel, R., and Woolard, J. (2003). Monitoring predators to optimize their management for marine turtle nest protection. Biological Conservation 113, 171-178. doi:10.1016/S0006-3207(02)00295-1

Engeman, R. M., Martin, R. E., Smith, H. T., Woolard, J., Crady, C. K., Shwiff, S. A., Constantin, B., Stahl, M., and Griner, J. (2005). Dramatic reduction in predation on sea turtle nests through improved predator monitoring and management. Oryx 39, 318-326. doi:10.1017/S0030605305000876

Epperson, J., III. (2005). Large Gambian rats worry Florida officials. Key West Citizen 3 January 2005, A-1.

Fiedler, L. (1988). Rodent problems in Africa. In 'Rodent Pest Management'. (Ed. I. Prakash.) pp. 35-65. (CRC Press: Boca Raton, FL.)

Fiedler, L. (1994). 'Rodent Pest Management in Eastern AFRICA.' FAO Plant Production and Protection Paper No. 123. (FAO: Rome.)

Florida Natural Areas Inventory (FNAI) (1990). 'Guide to the Natural Communities of Florida.' (Florida Natural Areas Inventory and Florida Department of Natural Resources: Tallahassee, FL.)

Gretillat, S., Mattei, X., and Marchand, B. (1981). A new rickettsiale of Gambia rats (Cricetomys gambianus) in Senegal: Grahamella kaniae n. sp. (Bartonellacae). Revue d'Elevage et de Medecine Veterinaire des Pays Tropicaux 34, 383-389.
Hayssen, V., Van Tienhoven, A., and Van Tienhoven, A. (1993). 'Asdell's Patterns of Mammalian Reproduction: a Compendium of Species Specific Data.' (Comstock/Cornell University Press: Ithaca, NY.)

Herder, S., Simo, G., Nkinin, S., and Njiokou, F. (2002). Identification of trypanosomes in wild animals from southern Cameroon using the polymerase chain reaction (PCR). Parasite 9, 345-349.

Hutin, Y., Williams, R. J., Malfait, P., Pebody, R., Loparev, V. N., Ropp, S. L., Rodriguez, M., Knight, J. C., Tshioko, F. K., Khan, A. S., Szczeniowski, M. V., and Esposito, J. J. (2001). Outbreak of human monkeypox, Democratic Republic of Congo, 1996-1997. Emerging Infectious Disease 7, 434-438.

Machang'u, R. S., Mgode, G. F., Assenga, J., Mhamphi, G., Weetjens, B., Cox, C., Verhagen, R., Sondij, S., Goris, M. G., and Hartskeerl, R. A. (2004). Serological and molecular characterization of leptospira serovar Kenya from captive African giant pouched rats (Cricetomys gambianus) from Morogoro Tanzania FEMS Immunology and Medical Microbiology 41, 117-121. doi:10.1016/ j.femsim.2004.02.002

Meshaka, W. E., Butterfield, B. P., and Hauge, J. B. (2004). 'The Exotic Amphibians and Reptiles of Florida.' (Krieger Publishing Company: Malabar, FL.)

Parker, I. M., Simberloff, D., Lonsdale, W. M., Goodell, K., Wonham, M., Kareiva, P. M., Williamson, M. H., Holle, B. V., Moyle, P. B., Byers, J. E., and Goldwasser, L. (1999). Impact: toward a framework for understanding the ecological effects of invaders. Biological Invasions 1, 3-19. doi:10.1023/A:1010034312781

Parkes, J., and Murphy, E. (2003). Management of introduced mammals in New Zealand. New Zealand Journal of Zoology 30, 335-359.

Perry, N. D., Hanson, B., Hobgood, W., Lopez, R. L., Okraska, C. R., Karem, K., Damon, I. K., and Carroll, D. S. (2006). New invasive species in southern Florida: Gambian rat (Cricetomys gambianus). Journal of Mammalogy 87, 262-264. doi:10.1644/05-MAMM-A132RR.1

Peterson, A. T., Papes, M., Reynolds, M., Perry, N. D., Hanson, B., Regnery, R., Hutson, C., Muizniek, B., Damon, I., and Carroll, D. (2006). Native range ecology and invasive potential of Cricetomys rats in North America. Journal of Mammaolgy 87, 427-432. doi:10.1644/05-MAMM-A-133R3.1

Rosevear, D. R. (1969). 'The Rodents of West Africa.' (British Museum of Natural History: London.)

Salmon, T., Whisson, D. A., and Gorenzel, W. P. (2000). Use of zinc phosphide for California ground squirrel control. In 'Proceedings of the Nineteenth Vertebrate Pest Conference'. (Eds T. A. Salmon and A. C. Crabb.) pp. 346-357. (Vertebrate Pest Conference: University of California Davis, CA.)

SAS Institute (1996). 'SAS/STAT User's Guide.' (SAS Institute: Carey, NC.)

Searle, S. R., Casella, G., and McCulloch, C. E. (1992). 'Variance Components.' (Wiley \& Sons: New York.)

Smithers, R. (1983). 'The Mammals of the Southern African Subregion.' (University of Pretoria: Pretoria, South Africa.)

Snow, R. W., and Oberhofer, L. (2004). Disposable pets, unwanted giants: pythons in Everglades National Park. In 'Natural Resource Year in Review - 2004'. P. 35. (National Park Service: Denver, CO.)

Tobin, M. E., Engeman, R. M., and Sugihara, R. T. (1994). Effects of initial rat captures on subsequent capture success of traps. In 'Sixteenth Vertebrate Pest Conference'. pp. 101-105. (Eds W. S. Halverson and A. C. Crabb.)

USA Congress (1993). 'Harmful Non-indigenous Species in the United States.' (Office of Technology Assessment, OTA-F-565, Government Printing Office: Washington, DC.) 
US Department of Agriculture/Animal and Plant Health Inspection Service, US Department of Agriculture/Forest Service and Department of Interior/Bureau of Land Management (1997). 'Animal Damage Control Program Final Environmental Impact Statement (Revised).' (USDA/APHIS: Washington, DC.)

Western, D. (1974). The distribution, density, and biomass density of lizards in a semi-arid environment of northern Kenya. East African Wildlife Journal 12, 49-62.
Wilcove, D. S., Rothstein, D., Dubow, J., Phillips, A., and Losos, E. (1998). Assessing the relative importance of habitat destruction, alien species, pollution, over-exploitation, and disease. Bioscience 48, 607-616. doi: $10.2307 / 1313420$

Manuscript received 2 February 2006, accepted 26 July 2006 